\title{
Measurement of some radioactive elements in drinking water in Arar city, Saudi Arabia
}

\author{
Mahmoud Ibrahim, Osama Shalabiea, Hassan Diab \\ Northern Border University, Arar, Saudi Arabia \\ Email address: \\ mahmoudbio@yahoo.com (M. Ibrahim)
}

\section{To cite this article:}

Mahmoud Ibrahim, Osama Shalabiea, Hassan Diab. Measurement of some Radioactive Elements in Drinking Water in Arar City, Saudi Arabia. American Journal of Life Sciences. Vol. 2, No. 1, 2014, pp. 24-28. doi: 10.11648/j.ajls.20140201.13

\begin{abstract}
Exposure to radioactive elements or having them through drinking water causes many biological risks. Therefore, it is important to investigate the drinking water especially in regions where people depend on well water for drinking. Concentrations of some radionuclides in some water wells, in Arar city of Saudi Arabia, were measured by using Hyper Pure Germanium (HPGe) Detector. Concentrations of ${ }^{226} \mathrm{Ra}$ (Radium), ${ }^{232} \mathrm{Th}$ (Thorium) and ${ }^{40} \mathrm{~K}$ (Potassium) were measured in drinking water of 5 water Selling Stations from different water wells; Alshark, Alsahab, Ghdeer, Katr Elnada and Almohamadia. The radiation hazard indices of water were also calculated. The results showed that the average values of either radionuclides concentration or radiation hazard indices of all water stations under study were in the internationally permissible range. Results therefore emphasize that the investigated wells from which the water was taken are suitable for drinking concerning the measured radionuclides. The work recommends more studies to investigate another radionuclides might be present in the drinking water.
\end{abstract}

Keywords: Wells Water, Radionuclides, Hazard Indices

\section{Introduction}

Natural environmental radioactivity and the associated external exposure due to gamma radiation depend mainly on the local geological and geographical conditions and appear at different levels in each region in the World [1]. The natural terrestrial gamma dose rate is an important contributor to the average dose received by the world's population $[2,3]$. Estimation of the radiation dose distribution is vital in assessing the health risk to a population and serves as a reference for documenting changes in environmental radioactivity due to anthropogenic activities [4]. Monitoring for radioactive materials is therefore of primary importance for humans, organisms and for environmental protection. Rapid and accurate methods for the assay of radioactivity are also essential [5] when outdoors humans are exposed to natural terrestrial radiation that originates predominantly from the upper $30 \mathrm{~cm}$ of the soil [6]. Humans are also exposed by contamination of the food chain which occurs as a result of direct deposition of radionuclides on plant leaves, root uptake from contaminated soil, sediment or water [7], and from direct ingestion of contaminated water [8]. To assess these exposures, radioactivity studies have been previously carried out in water samples $[8,9]$.
The present study assesses the specific activities and examines some of the radiation hazard indices of these naturally occurring radionuclides $\left({ }^{226} \mathrm{Ra},{ }^{232} \mathrm{Th}\right.$ and $\left.{ }^{40} \mathrm{~K}\right)$ in water samples from five groundwater sites in Arar using $\gamma$-ray spectrometry. These sites have been vulnerable to oil spill pollution, oil related effluent discharges, gas flare and other anthropogenic activities, which may enhance the natural radioactivity level of the area and human exposure. The values reported in this study constitute a baseline for radioactivity in the study area as no such study has been carried out in this area before.

\section{Materials and Methods}

\subsection{Sample Collection and Preparation Techniques}

Ten samples of water were collected from five selling water stations which receive their water from different water wells on which people in Arar are used to depend for drinking. Water samples were collected in plastic bottles and then acidified with $11 \mathrm{M}$ of HCL at the rate of $10 \mathrm{~mL}$ per liter of sample immediately after sample collection to avoid adsorption of radionuclides onto the walls of the containers [10]. Marinelli beakers of $1 \mathrm{~L}$ capacity rinsed with dilute $\mathrm{H}_{2} \mathrm{SO}_{4}$ and dried to avoid contamination, were filled with 
known volumes $(500 \mathrm{~mL})$ of the water sample. The beakers were subsequently firmly sealed for at least four weeks to ensure a state of secular equilibrium between radium isotopes and their respective daughters [10]. Each sample was then counted by using Hyper Pure germanium Detector.

\subsection{Hyper Pure Germanium (HPGe) Detector}

HPGe detectors are made by highly refining the element germanium and growing it into a crystal. The crystal goes through a series of processing steps culminating in the attachment of positive and negative contacts which turn it into an electronic diode. The special property of this diode is that it conducts current in proportion to the energy of a photon (gamma ray) depositing energy in it. The relationship between energy and current is so precise in HPGe detectors that energies are determined to better than 1/10th of 1 percent.

Due to its far superior resolution, HPGe can provide a sufficient information to accurately and reliably identify radionuclide's from their passive gamma ray emissions. It has 20-30 times better resolution than $\mathrm{NaI}$ detectors. Also, unlike $\mathrm{NaI}$ detectors, HPGe detectors are resistant to information (signal) degradation caused by changes in background radiation, shielding, multiple radionuclide interference, and temperature variations.

The activity concentrations of ${ }^{226} \mathrm{Ra},{ }^{232} \mathrm{Th}$ and ${ }^{40} \mathrm{~K}$ in the samples were measured using a coaxial HPGe detector, model GC3018e7500SL (serial number 693085, Canberra $\mathrm{GMbH}$, Germany). The relative efficiency of the detector is $30 \%$ and it has a resolution of $1.8 \mathrm{keV}$ at $1.33 \mathrm{MeV}$. The detector was maintained in a vertical position in a lead cylindrical shield of $10 \mathrm{~cm}$ thickness. The detector was coupled to a computer through a preamplifier base (Model 2002 CSL, Canberra GMbH, Germany). The spectrometer was calibrated for energy and efficiency using a standard source from Amersham Buchier GMbH \& Co. KG over a range from $20.01 \mathrm{keV}$ to $2.87 \mathrm{MeV}$. The initial comprehensive calibration used reference source R6/120/85 (QCY-48 solution) from Amersham. Subsequently, solutions 97-273 (a 51Cr solution) and 12024 (a 137Cs solution) were used to check the reproducibility of results and the stability of the counting system. These are all aqueous solutions which contain well known activity concentrations (Bq.Lit ${ }^{-1}$ ) of several gamma emitting isotopes across a wide range of energies between $60 \mathrm{keV}$ and $2 \mathrm{MeV}$. Dry quartz sand, free of natural radioactivity, was used as a matrix to simulate our samples. The quartz sand was carefully mixed with the nuclide solutions and dried at low temperature until constant mass was attained and measured.

The radioactivity concentrations of ${ }^{226} \mathrm{Ra}$ and ${ }^{232} \mathrm{Th}$ were determined from the photo peaks of ${ }^{214} \mathrm{~Pb}(295.20 \mathrm{keV})$ and ${ }^{212} \mathrm{~Pb}(238.64 \mathrm{keV})$ respectively, while ${ }^{40} \mathrm{~K}$ was determined from the $1460.8 \mathrm{keV}$ photo peak. Each sample was counted for $20,000 \mathrm{~s}$ to reduce statistical uncertainty. The activity of each sample was determined using the total net counts under the selected photo peaks after subtracting appropriate background counts and applying appropriate factors for photo peak efficiency, gamma intensity of the radionuclides and weight/volume of the sample [3]. The overall uncertainties in the measured concentrations were estimated from the parameters contained in the above mentioned processes, the calibration procedure, the peak area determination and the background.

\subsection{Calculation of Radiation Hazard Indices}

It is justifiable to exploit as many as possible of the known radiation health hazard indices to achieve a safe conclusion on the health status of an exposed person or environment. To represent the activity levels of ${ }^{226} \mathrm{Ra},{ }^{232} \mathrm{Th}$ and ${ }^{40} \mathrm{~K}$ by a single quantity, which takes into account the radiation hazards associated with each component, a common radiological index has been introduced [11]. This index is called the Radium Equivalent activity $\left(\mathrm{Ra}_{\mathrm{eq}}\right)$ which is defined mathematically by the following equation [1]:

$$
\mathrm{Ra}_{\mathrm{eq}}=\mathrm{C}_{\mathrm{Ra}}+1.43 \mathrm{C}_{\mathrm{Th}}+0: 077 \mathrm{C}_{\mathrm{K}}
$$

where $\mathrm{C}_{\mathrm{Ra}}, \mathrm{C}_{\mathrm{Th}}$ and $\mathrm{C}_{\mathrm{K}}$ are the activity concentrations of ${ }^{226} \mathrm{Ra},{ }^{232} \mathrm{Th}$ and ${ }^{40} \mathrm{~K}$ respectively. In the above relation, it has been assumed that $10 \mathrm{~Bq} . \mathrm{L}^{-1}$ of ${ }^{226} \mathrm{Ra}, 7 \mathrm{~Bq} \cdot \mathrm{L}^{-1}$ of ${ }^{232} \mathrm{Th}$ and $130 \mathrm{~Bq} . \mathrm{L}^{-1}$ of ${ }^{40} \mathrm{~K}$ produce equal gamma dose. The absorbed dose rates (D) due to gamma radiation in air at $1 \mathrm{~m}$ above the ground surface, assuming uniform distribution of the naturally occurring radionuclides $\left({ }^{226} \mathrm{Ra},{ }^{232} \mathrm{Th}\right.$ and $\left.{ }^{40} \mathrm{~K}\right)$ have been calculated as described in reference [1]. It has been assumed that the contributions from other naturally occurring radionuclides were insignificant. Therefore, D can be calculated according to UNSCEAR (2000) as:

$$
\mathrm{D}\left(\mathrm{nGy} \mathrm{h}^{-1}\right)=0.462 \mathrm{C}_{\mathrm{Ra}}+0.621 \mathrm{C}_{\mathrm{Th}}+0.0417 \mathrm{C}_{\mathrm{K}}
$$

To estimate the annual effective dose rates, the conversion coefficient from absorbed dose in air to effective dose is 0.7 $\mathrm{mSv} \cdot \mathrm{y}^{-1}$ and an outdoor occupancy factor $(0.2)$ in reference [1], are used. Therefore, the annual effective dose rate $\left(\mathrm{mSv} \cdot \mathrm{y}^{-1}\right)$ was calculated by the formula as follows:

$$
\begin{gathered}
\mathrm{D}_{\text {eff }}=\mathrm{D}\left(\mathrm{nGy}^{-\mathrm{h}^{-1}}\right) \times 8760 \text { h. } \mathrm{y}^{-1} \times 0.7 \times\left(10^{3} \mathrm{mSv} / 109\right) \mathrm{Gy} \times 0.2 \\
\mathrm{D}_{\text {eff }}=\mathrm{D} \times 1.21 \times 10^{-{ }^{3}} \mathrm{mSv} \cdot \mathrm{y}^{-}{ }^{1}
\end{gathered}
$$

The widely used hazard indices which reflect both external and internal exposure called the hazard indices $\left(\mathrm{H}_{\mathrm{ex}}\right.$ and $\left.\mathrm{H}_{\text {in }}\right)$ respectively as described in reference [1] are defined as follows:

$$
\begin{aligned}
\mathrm{H}_{\mathrm{ex}} & =\mathrm{C}_{\mathrm{Ra}} / 370+\mathrm{C}_{\mathrm{Th}} / 259+\mathrm{C}_{\mathrm{K}} / 4810 \\
\mathrm{H}_{\mathrm{in}} & =\mathrm{C}_{\mathrm{Ra}} / 185+\mathrm{C}_{\mathrm{Th}} / 259+\mathrm{C}_{\mathrm{K}} / 4810
\end{aligned}
$$

The values of the indices $\left(\mathrm{H}_{\mathrm{ex}}\right.$ and $\left.\mathrm{H}_{\mathrm{in}}\right)$ must be less than unity for the radiation hazard to be of negligible value [11].

\section{Results and Discussion}

From the gamma spectrometric analysis, three natural radionuclides were determined $\left({ }^{226} \mathrm{Ra},{ }^{232} \mathrm{Th}\right.$ and $\left.{ }^{40} \mathrm{~K}\right)$ in the water samples. Table 1 represents the results of the activity 
concentrations in water samples taken from 5 selling stations in the city under study.

As it can be seen from Table 1 and Figures 1,2 and 3, the concentration of $226 \mathrm{Ra}$ in water of the all stations ranges from $11 \pm 1.3$ Bq.L-1 of Almohamadia station to $33 \pm 2.6$ Bq.L-1 of Alshark station. Concerning 232Th and 40K, Almohamadia station recorded lower concentrations $9 \pm 2.4$ and $63 \pm 1.6 \mathrm{~Bq} . \mathrm{L}-1$ respectively while Alshark station recorded $27 \pm 2.1$ Bq.L-1 of $232 \mathrm{Th}$ and $250 \pm 1.3$ Bq.L-1 of $40 \mathrm{~K}$ respectively.

Table 1. The average activity concentrations of the radionuclides in water

\begin{tabular}{llll}
\hline Water station & ${ }^{226} \mathbf{R a}\left(\mathbf{B q} \cdot \mathbf{L}^{-\mathbf{1}}\right)$ & ${ }^{232} \mathbf{T h}\left(\mathbf{B q} \cdot \mathbf{L}^{-\mathbf{1}}\right)$ & ${ }^{{ }^{40} \mathbf{K}\left(\mathbf{B q} \cdot \mathbf{L}^{-\mathbf{1}}\right)}$ \\
\hline Alshark & $33 \pm 2.6$ & $27 \pm 2.1$ & $250 \pm 1.3$ \\
Alsahab & $19 \pm 2.2$ & $20 \pm 3.6$ & $180 \pm 2.5$ \\
Ghadeer & $15 \pm 2.1$ & $12 \pm 1.4$ & $140 \pm 3.1$ \\
Katr Elnada & $13 \pm 3.6$ & $11 \pm 1.3$ & $80 \pm 2.4$ \\
Almoham-adia & $11 \pm 1.3$ & $9 \pm 2.4$ & $63 \pm 1.6$ \\
\hline
\end{tabular}

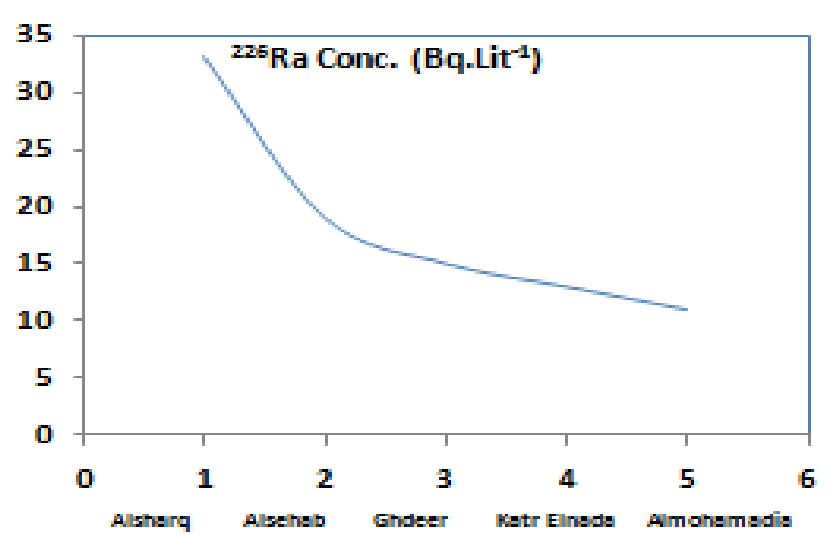

Fig 1. The average concentrations of the ${ }^{226} \mathrm{Ra}$ in the five water stations

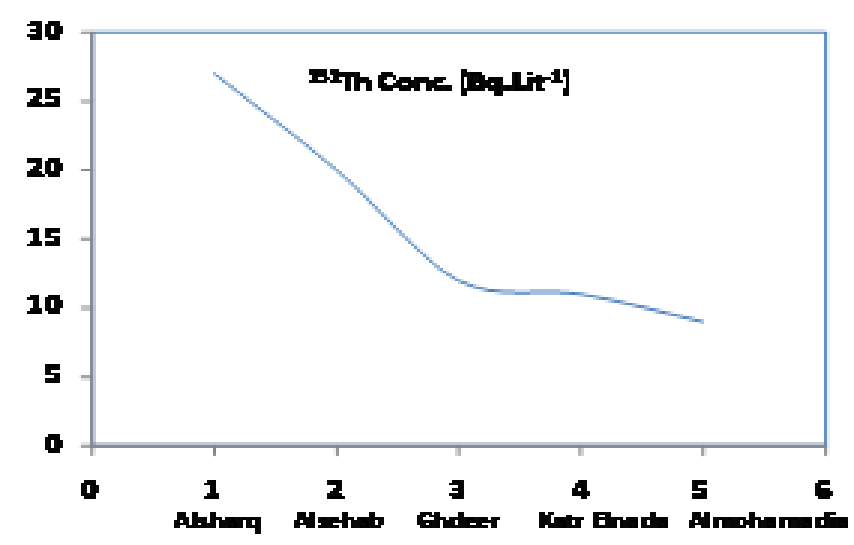

Fig 2. The average concentrations of the ${ }^{232}$ Th in the five water stations

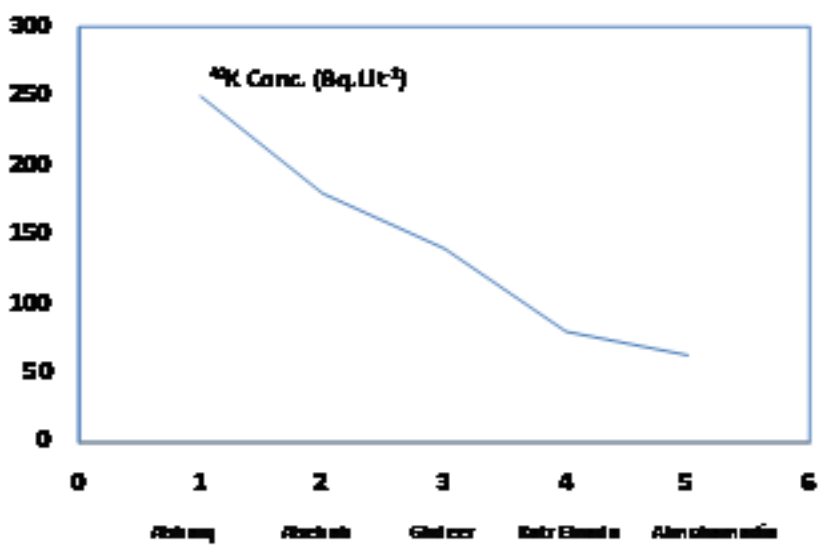

Fig 3. The average concentrations of the ${ }^{40} \mathrm{~K}$ in the five water stations

These concentrations are a little bit higher than those obtained in river water in Tanzania [12]. However, all the measured values are within the worldwide average concentrations of these natural radionuclides in drinking water as reported by the United Nations of Scientific Committee of the Effects of Atomic Radiation (UNSCEAR) [1] and other studies [3,4,11]. The levels of radioactivity measured in wells are usually higher than in flowing or well waters because a significant proportion of the radioactivity transported by rivers into wells accumulates there [8].

This may explain the reported values in these wells being slightly higher than those reported in reference [13]. The relatively high activity concentration observed in the well may be attributed to increased anthropogenic activities in that area (oil exploration activities and frequent oil spills into the environment). The abundance of ${ }^{40} \mathrm{~K}$ activity observed in the wells may be due to heavy agricultural activities going on in the area that involve the use of potassium fertilizers which may have been transported to the uncultivated sampled spots through one or more pollution transport mechanisms, given that ${ }^{40} \mathrm{~K}$ is a highly soluble element [13]. The level of ${ }^{232} \mathrm{Th}$ observed may be due to the geology of the area (including the presence of metamorphic rocks like shale). However, a detailed geochemical investigation is required to reach a definite conclusion on causes. The radium equivalent activities due to the presence of naturally occurring terrestrial radionuclides ${ }^{226} \mathrm{Ra},{ }^{232} \mathrm{Th}$ and ${ }^{40} \mathrm{~K}$ were calculated based on their activities in soils and sediments determined by gamma-ray spectrometry and using equation (1). The external gamma dose rates were calculated based on their activities in water samples using equation (2).

The dose rates generally varied from 12 to $63 \mathrm{nGyh}^{-1}$ with a mean value of $30 \pm 5.5 \mathrm{nGyh}^{-1}$ which is within the range of values given in UNSCEAR (2000) report $\{57$ (18-93) nGy $\left.\mathrm{h}^{-1}\right\}$. The outdoor annual effective doses ranged from 15 to $77 \mathrm{mSv}^{-1}$ with a mean value of $37 \pm 6.8 \mathrm{mSv} \mathrm{y}^{-1}(0.037$ $\mathrm{mSv} \mathrm{y}^{-1}$ ) as calculated using equation (3) for the wells, while the worldwide average annual effective dose is approximately $0.5 \mathrm{mSv} \mathrm{y}^{-1}$ and the results for individual countries being generally within $0.3-0.6 \mathrm{mSv} \mathrm{y}^{-1}$ range $[1,3]$. Thus, these results are approximately one order of 
magnitude less than the average worldwide limits $(0.05 \mathrm{mSv}$ $\left.\mathrm{y}^{-1}\right)$ as reported by reference [1]. The external hazard index Hex was calculated using equation (4). Its values ranged from 0.07 to 0.35 with a mean of 0.17 . The internal hazard index $\mathrm{H}_{\text {in }}$ was calculated using equation (5), the value of $\mathrm{H}_{\text {in }}$ ranged from 0.10 to 0.46 with a mean value of 0.23 . The values of $\mathrm{H}_{\mathrm{ex}}$ and $\mathrm{H}_{\mathrm{in}}$ of all samples studied in this work are far less than unity.

Table 2. The radiation hazard indices of collected water samples

\begin{tabular}{cccccc}
\hline LOCATION & $\begin{array}{c}\mathbf{R a}_{\text {eq }} \\
\left(\mathbf{B q .}^{-\mathbf{1}}\right)\end{array}$ & $\mathbf{D}\left(\mathbf{n G y} \mathbf{h}^{-}\right)$ & $\begin{array}{c}\mathbf{E f f} \mathbf{D o s e} \\
\left(\boldsymbol{\mu S v} \mathbf{y}^{-1}\right)\end{array}$ & $\mathbf{H}_{\mathbf{e x}}$ & $\mathbf{H}_{\text {in }}$ \\
\hline Alshark & $\mathrm{NiL}$ & $15 \pm 2.3$ & $21 \pm 2.3$ & 0.07 & 0.11 \\
Alsahab & $\mathrm{NiL}$ & $12 \pm 1.3$ & $17 \pm 1.5$ & 0.07 & 0.09 \\
Ghadeer & $\mathrm{NiL}$ & $11 \pm 3.4$ & $16 \pm 1.6$ & 0.05 & 0.08 \\
$\begin{array}{c}\text { Katr Elnada } \\
\text { Almohama- } \\
\text { dia }\end{array}$ & $\mathrm{NiL}$ & $10 \pm 2.6$ & $11 \pm 3.2$ & 0.45 & 0.77 \\
\hline
\end{tabular}

The concentration of radionuclides and heavy metals in ground water from 6 wells in Makkah and 4 wells in Taif cities (both in Saudi Arabia) were measured using high resolution $\gamma$-rays spectrometer and inductively coupled plasma optical emission spectrometry (ICP-OES), respectively [14]. The groundwater showed levels of 0.017-0.088, 0.015-0.137, 0.020-0.102 and 0.41-1.0 Bq.L-1 for $238 \mathrm{U}, 226 \mathrm{Ra}, 232 \mathrm{Th}$ and $40 \mathrm{~K}$, respectively. These results indicate that the levels of the natural radioactivity in groundwater are comparable with the corresponding values in groundwater and surface water of other countries. Radioisotopes level is much lower than the WHO, EPA and FPT guidelines. The $\mathrm{Ba}, \mathrm{Fe}, \mathrm{Co}, \mathrm{V}, \mathrm{Zn}, \mathrm{Se}, \mathrm{Tl}, \mathrm{Cd}, \mathrm{Cr}$, As and $\mathrm{Cu}$ contents in groundwater were determined while the levels of $\mathrm{Pb}, \mathrm{Ni}, \mathrm{Mg}, \mathrm{Ag}, \mathrm{Be}$ and $\mathrm{Al}$ were under detection limits. The heavy metals content in groundwater collected from Makkah and Taif cities are much lower than those measured in groundwater and surface water of other countries and the guideline values. The hierarchical cluster analysis was performed on the available dataset of radioactivity concentrations and heavy metals content using Ward method. The overall annual effective doses (with mean of $16.5 \mu \mathrm{Sv} \mathrm{y}-1$ ) from $238 \mathrm{U}, 226 \mathrm{Ra}$ and $232 \mathrm{Th}$ isotopes were below the WHO recommended reference level [15].

\section{Conclusions}

The natural radioactivity levels of ${ }^{226} \mathrm{Ra},{ }^{232} \mathrm{Th}$ and ${ }^{40} \mathrm{~K}$ have been measured in water samples in five wells using gamma ray spectroscopy. The activity profiles of the radionuclides have clearly showed low activity concentrations across the study area. The mean activity concentrations of ${ }^{226} \mathrm{Ra},{ }^{232} \mathrm{Th}$ and ${ }^{40} \mathrm{~K}$ were $18.2 \pm 2.4,15.8$ \pm 2.16 and $142 \pm 2.18 \mathrm{~Bq} . \mathrm{L}^{-1}$ respectively. Therefore, the water of the area have no immediate health implication for the inhabitants and they can be used as without posing any significant radiological threat to the population, while the water is radiologically safe (concerning the radionuclides under study) for use in domestic and industrial purposes. This work has established baseline information on the natural radioactivity status of five Arar wells, which will serve as a reference for future studies. We recommend that normal occupational health and environmental protection measures designed for non-radiological hazards in the environment are sufficient to protect against any future natural radiological hazard that may arise in the area. However, further study may be necessary to estimate the external and internal doses from other suspected radiological sources within Saudi Arabia.

\section{Acknowledgement}

The authors would like to thank the Deanship of Scientific Research, Northern Border University, Saudi Arabia which supported this work financially. The help and scientific advises of Prof. M. Ghannam, King Saud university, Saudi Arabia are deeply appreciated.

\section{References}

[1] (UNSCEAR), Sources and Effects of Ionizing Radiation (Report to the General Assembly). United Nation, New York, 2000 .

[2] M.Y. Tso, J.K Leung, "Population dose distribution due to natural radiations in Hong Kong", Health Phys. Vol 8, $555-578,2000$.

[3] B. Senthilkumar, V, Dhavamani, S. Ramkuma, and P. Philominathan, "Measurement of gamma radiation levels in soil samples from Thanjavur, using g-ray spectrometry and estimation of population exposure". J. Med. Phys. Vol 35, pp. 48-53, 2010.

[4] Obed, R.I., Farai, I.P., Jibiril, N.N., 2005. Population dose distribution due to soil radioactivity concentration levels in 18 cities across Nigeria. J. Radiol. Prot. Vol 25, pp. 305-312, 2004.

[5] S.M. El-Bahi, "Assessment of radioactivity and radon exhalation rate in Egyptian cement. Health Phys. 86, $517 \mathrm{e} 522$.

[6] K. Chikasawa, T. Ishii, and H. Ugiyama, "Terrestrial gamma radiation in Kochi prefecture", Japan. J. Radiol. Prot. Vol 25, pp. 305-312, 2001.

[7] G.O. Avwiri, O.E. Agbalagba, "Survey of gross alpha and gross beta radionuclide activity in Okpare Creek, delta State, Nigeria”, Asian Network for Sci. Infor. J. Appl. Sci. vol 7 (22), pp. 542-3547, 2007.

[8] R.O. Onoja, "Survey of gross alpha and beta radioactivity in well water from Zaria area", M.Sc. thesis, ABU Zaria, Nigeria, 2004.

[9] G.O. Avwiri, O.E. Agbalagba, and P.I. Enyinna, "Terrestrial radiation around oil and gas facilities in Ughelli Nigeria. Asian Network for Science information". J. Appl. Sci. 7 (11), pp. 543-1546, 2007. 
[10] R.A. Onoja, "Total radioactivity count in taps and well water around Zaria area, Kaduna State, Nigeria". Ph.D. thesis, ABU, Zaria. Nigeria, 2010.

[11] H.m. Diab, S.A. Nouh, A. Hamdy, and S.A El-Fiki, "Evaluation of natural radioactivity in a cultivated area around a fertilizer factory". J. Nucl. Rad. Phys. 3 (1), pp.53-62, 2008.

[12] K. Najat, M. Mohammed and S. Mazunga. "Natural Radioactivity in Soil and Water from Likuyu Village in the Neighborhood of Mkuju , Tanzania. J of Analytical Chemistry", Article ID 501856, 4 pages, 2013.
[13] E.O. Agbalagba, R.A. Onoja, R.A "Evaluation of natural radioactivity in soil, sediment and water samples of Nigeria Delta (Biseni) flood plain lakes, Nigeria" journal of Environmental Radioactivity vol 102, pp. 667-671, 2011.

[14] Sh. Taher, H. Hassan and A. Abdulqader. Natural Radioactivity and Heavy Metals Level in Some Well Waters in Makkah Region, Saudi Arabia. 2011

[15] T. Sharshar, A. Aydarous, H.E. Hassan, H.A. Arida. Natural Radioactivity and Heavy Metals Level in Some Well Waters. Arab Journal of Nuclear Science and Applications 06/2012; 45(2):47-56. 